\title{
Halogen Chemistry on Catalytic Surfaces
}

\author{
Maximilian Moser ${ }^{\S}$ and Javier Pérez-Ramírez* \\ §SCS-Metrohm Award for best oral presentation in Catalysis Science and Engineering
}

\begin{abstract}
Halogens are key building blocks for the manufacture of high-value products such as chemicals, plastics, and pharmaceuticals. The catalytic oxidation of $\mathrm{HCl}$ and $\mathrm{HBr}$ is an attractive route to recover chlorine and bromine in order to ensure the sustainability of the production processes. Very few materials withstand the high corrosiveness and the strong exothermicity of the reactions and among them $\mathrm{RuO}_{2}$ and $\mathrm{CeO}_{2}$-based catalysts have been successfully applied in $\mathrm{HCl}$ oxidation. The search for efficient systems for $\mathrm{HBr}$ oxidation was initiated by extrapolating the results of $\mathrm{HCl}$ oxidation based on the chemical similarity of these reactions. Interestingly, despite its inactivity in $\mathrm{HCl}$ oxidation, $\mathrm{TiO}_{2}$ was found to be an outstanding $\mathrm{HBr}$ oxidation catalyst, which highlighted that the latter reaction is more complex than previously assumed. Herein, we discuss the results of recent comparative studies of $\mathrm{HCl}$ and $\mathrm{HBr}$ oxidation on both rutile-type $\left(\mathrm{RuO}_{2}, \mathrm{IrO}_{2}\right.$, and $\left.\mathrm{TiO}_{2}\right)$ and ceria-based catalysts using a combination of advanced experimental and theoretical methods to provide deeper molecular-level understanding of the reactions. This knowledge aids the design of the next-generation catalysts for halogen recycling.
\end{abstract}

Keywords: Ceria-zirconia · Hydrogen halides · Oxidation · Prompt gamma activation analysis · Rutile-type oxides.

\section{Introduction}

Halogens are widely applied as reactive intermediates in the synthesis of various commodities in the chemical, pharmaceutical, and plastics industry. ${ }^{[1]}$ However, about half of the halogens are reduced to undesired hydrogen halides and halide salts. The copious formation of $\mathrm{HCl}$ or $\mathrm{HBr}$ by-products is a serious challenge, since options to deal with this waste stream such as marketing or neutralization are unattractive. ${ }^{[1]}$ The recovery of $\mathrm{Cl}_{2}$ and $\mathrm{Br}_{2}$ from $\mathrm{HCl}$ and $\mathrm{HBr}$ has been recognized as the most appealing route in order to maintain an economically feasible and environmentally friendly process design. Amongst the available options, catalytic oxidation has been shown to be the most waste- and cost-efficient method to achieve this. ${ }^{[1,2]}$

The study of $\mathrm{HCl}$ oxidation dates back to the 1860 s, when Henry Deacon invent-

${ }^{\star}$ Correspondence: Prof. Dr. J. Pérez-Ramírez E-mail: jpr@chem.ethz.ch

Institute for Chemical and Bioengineering

Department of Chemical and Applied Biosciences

ETH Zurich

Vladimir-Prelog-Weg 1

$\mathrm{CH}-8093$ Zurich ed the process to recover chlorine for the Leblanc process..$^{[1 a, b]}$ The corrosiveness and the high exothermicity of the reaction was detrimental to the $\mathrm{CuCl}_{2}$-based catalyst, which suffered from volatilization of its active phase. The Deacon process was eventually abandoned in the 1890s due to substitution of the Leblanc process by the Solvay process. ${ }^{[1 a, b]}$ Still, various companies and researchers attempted throughout the $20^{\text {th }}$ century to improve the $\mathrm{Cu}$-based catalysts or to identify new systems..$^{[1 a, b]}$ At the turn of the millennium, $\mathrm{RuO}_{2}-$ based catalysts, developed independently by Sumitomo Chemicals and Bayer MaterialScience, were implemented as the new generation of highly active and stable $\mathrm{HCl}$ oxidation catalysts for chlorine recycling within the manufacture of polyurethanes and polycarbonates. ${ }^{[1 a]}$ In the continuous search for more alternative catalysts, other metal oxides such as $\mathrm{CeO}_{2}, \mathrm{U}_{3} \mathrm{O}_{8}$, and $\mathrm{CuCrO}_{2}$, have been discovered. ${ }^{[3]}$ In particular, ceria has received considerable attention, which pinnacled in the formulation of a technical $\mathrm{CeO}_{2} / \mathrm{ZrO}_{2}$ catalyst with stable performance in pilot studies. ${ }^{[4]}$

The development of an analogue catalytic $\mathrm{HBr}$ oxidation process was first attempted in the 1930s by George Hooker, who adopted the original Deacon concept. ${ }^{[5]} \mathrm{HBr}$ oxidation has been investigated by different companies in the past decades, but the implementation was inhibited due to the difficulties of identifying stable catalysts and a safe process. ${ }^{[2 \mathrm{~b}]}$ Research in bromine recovery was revi- talized when the increased production of unconventional natural gas prompted the potential use of $\mathrm{Br}_{2}$ to functionalize the inert alkanes into alkyl bromides for further conversion into fuels and chemicals.[1c,2a] The search for a cost-efficient bromine recovery process logically led to the investigation of $\mathrm{HCl}$ oxidation catalysts for $\mathrm{HBr}$ oxidation. $\mathrm{CeO}_{2}$-based and rutile-type (i.e. $\mathrm{RuO}_{2}$ and $\mathrm{IrO}_{2}$ ) materials have been shown to catalyze $\mathrm{HBr}$ oxidation, corroborating the anticipated chemical similarities of both reactions. ${ }^{[6]}$ However, the unexpected activity of $\mathrm{TiO}_{2}$ in $\mathrm{HBr}$ oxidation, despite its inactivity in $\mathrm{HCl}$ oxidation, underlined that the mechanism of $\mathrm{HBr}$ oxidation has features distinct from that of $\mathrm{HCl}$ oxidation. ${ }^{[7]}$ To close this gap in understanding, dedicated studies are needed to rationalize the relationship between the state of the surface and the apparent performance over both rutile-type and ceria-based catalysts in $\mathrm{HBr}$ oxidation.

In this article, we discuss the strategy for an integrated approach to halogen chemistry and present advanced methods, i.e. temporal analysis of products (TAP) and prompt gamma activation analysis (PGAA), as key techniques to experimentally analyze mechanistic aspects and the state of the catalyst surface under working conditions. We outline the interplay between the surface chemistry and the performance in $\mathrm{HCl}$ and $\mathrm{HBr}$ oxidation over rutile-type and ceria-based catalysts. We highlight the necessity to individually optimize the catalyst formulation for either $\mathrm{HCl}$ or $\mathrm{HBr}$ oxidation. 


\section{Integrated Approach to Halogen Chemistry}

Throughout the research on $\mathrm{HCl}$ and $\mathrm{HBr}$ oxidation, the study of the surface chemistry under working conditions has been hampered by the corrosiveness of the reactants. Mechanistic studies mostly emphasized on ex situ characterization such as X-ray diffraction (XRD), X-ray photoelectron spectroscopy (XPS), and high-resolution transmission electron microscopy (HRTEM), as well as molecularmodeling. ${ }^{[8]}$ Further, ultra-high vacuum (UHV) methods, such as the high-resolution core-level shift, enables the study of surface processes under reaction atmosphere over single $\mathrm{RuO}_{2}$ crystals. ${ }^{[9]}$ However, to connect the molecular-level studies on model surfaces to the apparent performance of real-life catalysts the pressure and materials gaps have to be closed.[10] For this purpose, an integrated approach was developed by combining different characterization techniques (Fig. 1a). The key methods of this strategy are theoretical studies using density functional theory (DFT), transient mechanistic studies using temporal analysis of products (TAP), ${ }^{[1]}$ and the quantification of the halogen uptake under working conditions with operando prompt gamma activation analysis (PGAA). ${ }^{[4,8 c, 12]}$

TAP is a highly advanced technique to study mechanisms of experimentally demanding reactions over industrially relevant catalysts. ${ }^{[10]}$ Small amounts $\left(10^{6}\right.$ molecules) of the reactants are pulsed over the catalyst bed and are analyzed by quadrupole mass spectroscopy (QMS) as shown in Fig. 1b. The reactants can be pulsed individually, simultaneously, or in pumpprobe fashion, i.e. with distinct time delay between individual reactant pulses. Key advantages of TAP comprise (i) a millisecond time resolution, (ii) the use of practical catalysts, (iii) excellent temperature control, and (iv) safe operation. These aspects make TAP a unique technology to bridge the pressure and material gap between UHV and real-life catalytic conditions. ${ }^{[10]}$

PGAA has been shown to be a direct and reliable method to determine the elemental composition of the catalysts under reaction conditions. ${ }^{[4,8 c, 12]}$ The working principle is based on radiative neutron capture, or $(n, \gamma)$ reaction upon irradiation of the sample with cold neutrons (Fig. 1c). The nuclei capture the neutrons and promptly emit typically 2 to 4 gamma rays in a cascade before returning to the ground state. The gamma radiation is characteristic, i.e. the energy values of the gamma rays identify the nuclide, and their intensities are proportional to the number of atoms present in the analyzed volume. The sensitivity and the detection limit of PGAA differ from element to element, and depend on the partial gamma-ray production cross-section, the detector efficiency and the level of the baseline at the analytical line. The dynamic range of the method is limited by either the too low sensitivity, such as for oxygen, or by the too high counting rate that overloads the counting system, e.g. with iridium. ${ }^{13]}$

\section{Surface Chemistry and Performance of Rutile-type Catalysts for Halogen Production}

$\mathrm{RuO}_{2}$-based materials are the current state-of-the-art catalysts for $\mathrm{HCl}$ oxidation and have received widespread attention amongst researchers, who aimed to understand the reaction mechanism and to lower the amount of precious ruthenium required in the catalyst composition. ${ }^{[14]}$ Besides $\mathrm{RuO}_{2}$, also $\mathrm{IrO}_{2}$ was discovered to be active in $\mathrm{HCl}$ oxidation. ${ }^{[15]}$ Both metal oxides comprise a dense rutile-type structure that inhibits the penetration of chlorine atoms into the subsurface layers. $\mathrm{IrO}_{2}$ operates, however, at much higher temperature compared to $\mathrm{RuO}_{2}$ due to its larger chlorine evolution barrier. With respect to the catalyst scale up, both metal oxides can be dispersed in the form of small nano layers or clusters on $\mathrm{TiO}_{2}$-rutile, which is due to lattice matching $\left(\mathrm{RuO}_{2}\right)$ or electronic effects $\left(\mathrm{IrO}_{2}\right)$. Owing to their robustness in $\mathrm{HCl}$ oxidation, both catalysts were considered potential candidates for a stable oxidation of $\mathrm{HBr}$. In fact, the comparison of their activities in $\mathrm{HCl}$ and $\mathrm{HBr}$ oxidation revealed that they oxidize $\mathrm{HBr}$ at much lower temperature (Fig. 2a). ${ }^{6]}$ The activity of $\mathrm{TiO}_{2}$ for $\mathrm{HBr}$ oxidation ${ }^{[7]}$ was not expected due to the inactivity in $\mathrm{HCl}$ oxidation which led to the commonly accepted theory that $\mathrm{TiO}_{2}$ cannot catalyze hydrogen halide oxidation due to its inability to adsorb and dissociate molecular oxygen. ${ }^{[16]}$

In-depth studies were undertaken to assess and compare the rutile-type catalysts in $\mathrm{HCl}$ and $\mathrm{HBr}$ oxidation. Despite its stability in $\mathrm{HCl}$ oxidation, $\mathrm{RuO}_{2}$ brominates in contrast to $\mathrm{TiO}_{2}$, which led to changes in the crystallinity observed by HRTEM and supported by $a b$ initio thermodynamics, suggesting that the replacement of lattice oxygen is more exothermic in $\mathrm{RuO}_{2}$ than $\mathrm{TiO}_{2}$, facilitating a strong bromination of the surface and subsurface (Fig. 2b). [17]

To shed light on the reaction mechanism, the surface of $\mathrm{TiO}_{2}$ was studied with XPS, which evidenced the formation of $\mathrm{Ti}^{3+}$ sites during the $\mathrm{HBr}$ oxidation; ${ }^{[7]}$ an indication of the formation of surface defects. Theoretical calculations on this defect formation ultimately proposed that the replacement of the bridge oxygen with a bromine atom is a self-doping mechanism that eventually enables the adsorption of molecular oxygen due to the smaller energetic barrier to transfer the electrons from the bromide to the oxygen (Fig. 2c). ${ }^{[7]}$ In contrast to that, the energetic barrier of the chlorine doped surface is too large to enable the activation of molecular oxygen on the surface.

DFT indicated that the reaction mech-

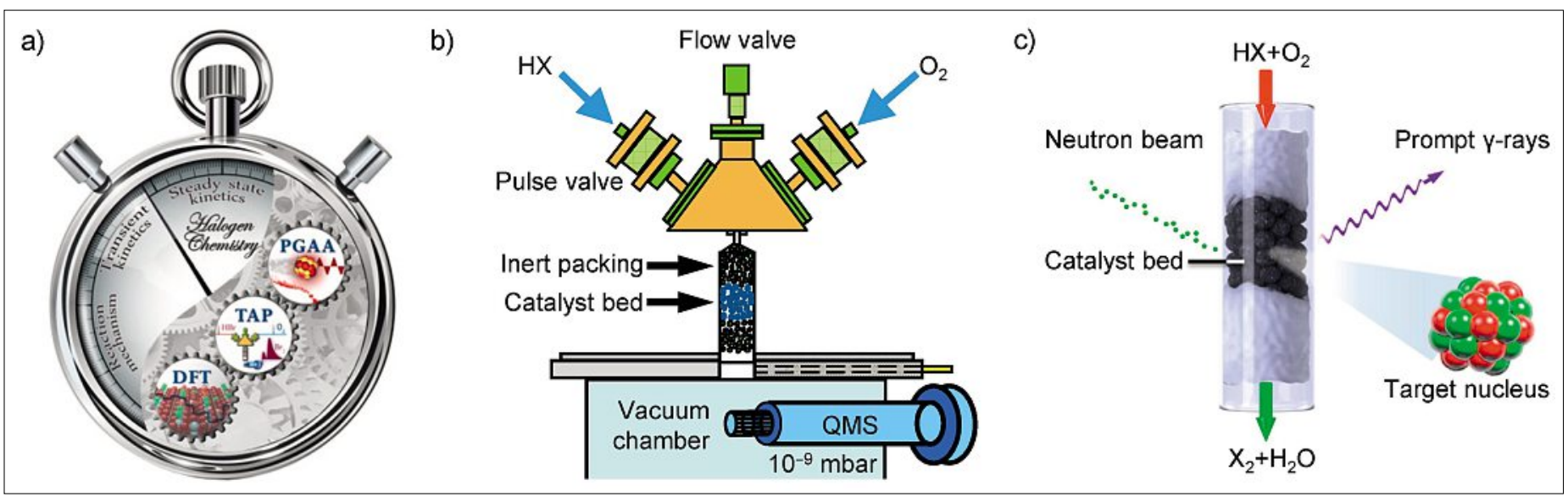

Fig. 1. The synchronization of advanced techniques bridges the pressure and materials gap between molecular studies and catalytic evaluation under working conditions (a). Transient mechanistic studies on real-life catalysts are conducted using TAP at millisecond time resolution (b). The uptake of halogens on the catalysts under working conditions is quantified using PGAA (c). 

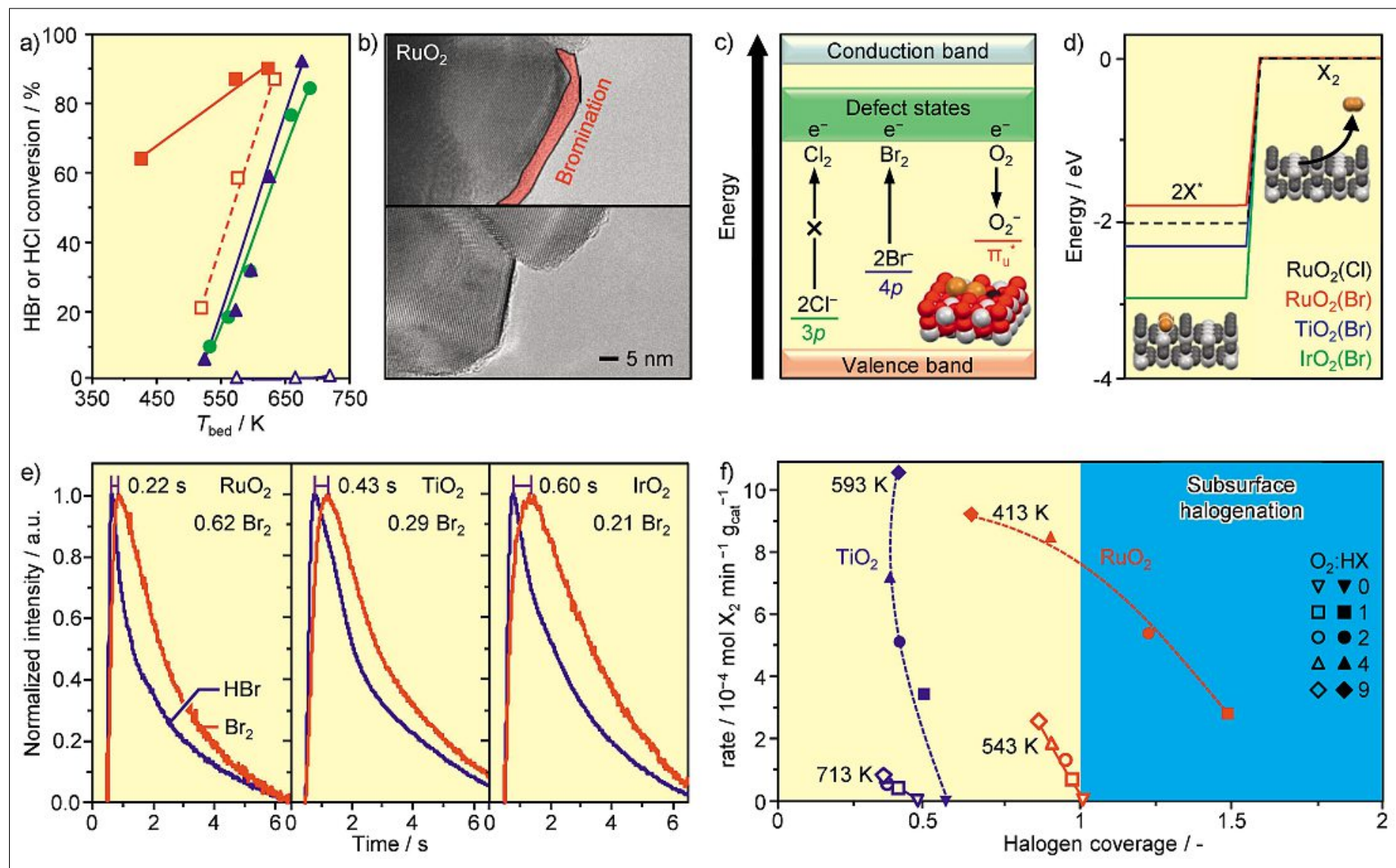

Fig. 2. Activity versus temperature for $\mathrm{RuO}_{2}$ (red), $\mathrm{IrO}_{2}$ (green) and $\mathrm{TiO}_{2}$ (blue) in $\mathrm{HCl}$ (dashed line) and $\mathrm{HBr}$ (solid lines) oxidation (a). $\mathrm{HRTEM}$ micrographs of $\mathrm{RuO}_{2}$ (b) treated in $\mathrm{HBr}$ (top) and $\mathrm{HCl}$ (bottom). Illustration of the band gap of the semiconductor $\mathrm{TiO}_{2}$ (c). DFT calculation for the halogen evolution on halogenated rutile-type surfaces (d). Normalized $\mathrm{HBr}$ and $\mathrm{Br}_{2}$ responses after simultaneous $\mathrm{HBr}$ and $\mathrm{O}_{2}$ pulsing for rutile-type catalysts (e). Activity versus halogen coverage over $\mathrm{TiO}_{2}$ and $\mathrm{RuO}_{2}$ in $\mathrm{HCl}$ (open symbols) and $\mathrm{HBr}$ (solid symbols) oxidation at different oxygen partial pressures (f).

anism follows the same path with bromine evolution as the most energy demanding step (Fig. 2d). ${ }^{[7]}$ The calculations were corroborated by TAP studies, which showed that the bromine evolution from the surface is the slowest step. Furthermore, the time delay between the $\mathrm{HBr}$ and the $\mathrm{Br}_{2}$ pulse increases in the order: $\mathrm{RuO}_{2}<\mathrm{TiO}_{2}<\mathrm{IrO}_{2}$, which is in agreement with the increase in the calculated energy barriers (Fig. 2e) ${ }^{[17]}$ This also supports that bromine evolution is easier on $\mathrm{TiO}_{2}$ than $\mathrm{IrO}_{2}$ and explains that the apparently similar activity of both catalysts in $\mathrm{HBr}$ oxidation results from a compensation effect between the surface coverage and the reaction kinetics. ${ }^{[7,17]}$

The quantitative determination of the halogen uptake under working conditions using PGAA demonstrates that $\mathrm{RuO}_{2}$ suffers from extensive subsurface bromination, at low $\mathrm{O}_{2}: \mathrm{HBr}$ ratios and temperatures, which agrees with the microscopic studies and $a b$ initio thermodynamics. $\mathrm{TiO}_{2}$ exhibits inherently low halogen coverage $(30-50 \%)$ at all conditions due to its unique defect-driven mechanism (Fig. 2f). ${ }^{[17]}$ In $\mathrm{HCl}$ oxidation, $\mathrm{TiO}_{2}$ is inactive and the chlorination of the active $\mathrm{RuO}_{2}$ is limited to the surface. Correlating the halogen uptake to the apparent performance ev- idenced the completely different behavior of the rutile materials under working conditions, which points to the need for further optimization of the stability of $\mathrm{RuO}_{2}$ if an application at low reaction temperatures is desired. One way could be the formulation of mixed Ru-Ti oxides to decrease the surface bromination and inhibit the penetration of bromine into the subsurface.

\section{Stability and Activity of Mixed $\mathrm{Ce}-\mathrm{Zr}$ Oxides in $\mathrm{HCl}$ and $\mathrm{HBr}$ Oxidation}

Similar stability issues, as seen for $\mathrm{RuO}_{2}$ in $\mathrm{HBr}$ oxidation, were already known from the case of $\mathrm{CeO}_{2}$ in $\mathrm{HCl}$ oxidation. ${ }^{[3 a} \mathrm{CeO}_{2}$ suffers from subsurface chlorination under harsh reaction conditions as evidenced by operando PGAA, forming stable and inactive cerium chloride. ${ }^{[12]}$ In an attempt to stabilize the $\mathrm{CeO}_{2}$ different support materials were investigated, which led to the discovery of the supported $\mathrm{CeO}_{2} / \mathrm{ZrO}_{2}$ systems. ${ }^{[4]}$ It was shown that the $\mathrm{ZrO}_{2}$ support reduced the chlorine uptake and increased the activity of $\mathrm{CeO}_{2}$ significantly, which was suggested to be linked to stabilization of $\mathrm{CeO}_{2}$ nanostruc- tures and the formation of $\mathrm{Ce}-\mathrm{Zr}$ mixed oxides. ${ }^{[4]}$ The formation of mixed $\mathrm{Ce}-\mathrm{Zr}$ oxides positively affects the performance in $\mathrm{HCl}$ oxidation due to improved redox properties and higher thermal stability. ${ }^{[13]}$ However, the impact of the catalyst's morphology, i.e. how well $\mathrm{Ce}$ and $\mathrm{Zr}$ have to be intermixed at an atomic or particle level to achieve these properties, was unknown.

To study the impact of zirconia on the performance of ceria, different ceriazirconia mixed oxides were prepared exhibiting distinct morphologies that are either homogeneous or non-homogeneous mixed $\mathrm{Ce}-\mathrm{Zr}$ oxides as shown by energydispersive X-ray spectroscopy (EDS) mapping (Fig. 3a). The catalytic performance in $\mathrm{HCl}$ oxidation of both materials is very comparable. ${ }^{[13]}$ However, in $\mathrm{HBr}$ oxidation distinctions became evident as the catalytic activity of non-homogeneous materials dropped more strongly within $40 \mathrm{~h}$ compared to the homogeneous mixed oxide (Fig. 3b).

PGAA studies on the different mixed $\mathrm{Ce}-\mathrm{Zr}$ oxides indicated that $\mathrm{CeO}_{2}$-based catalysts are more prone to bromination than chlorination (Fig. 3c,d), which is detrimental to their stability. The chlorine uptake under different reaction conditions 
a)
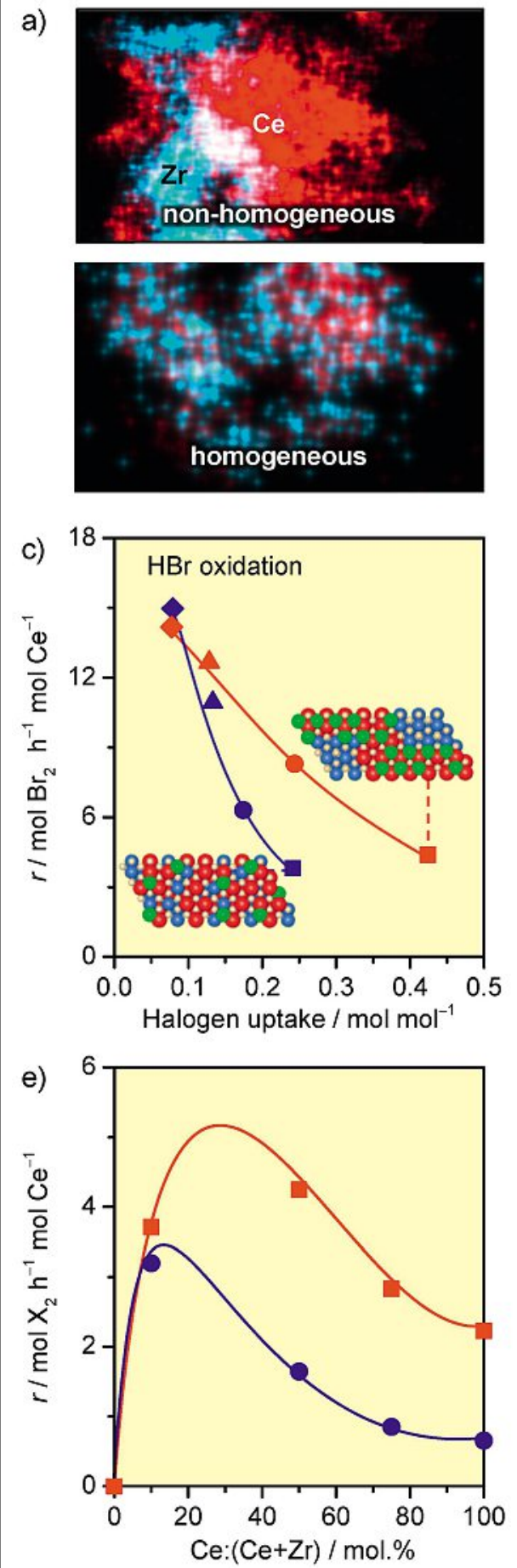
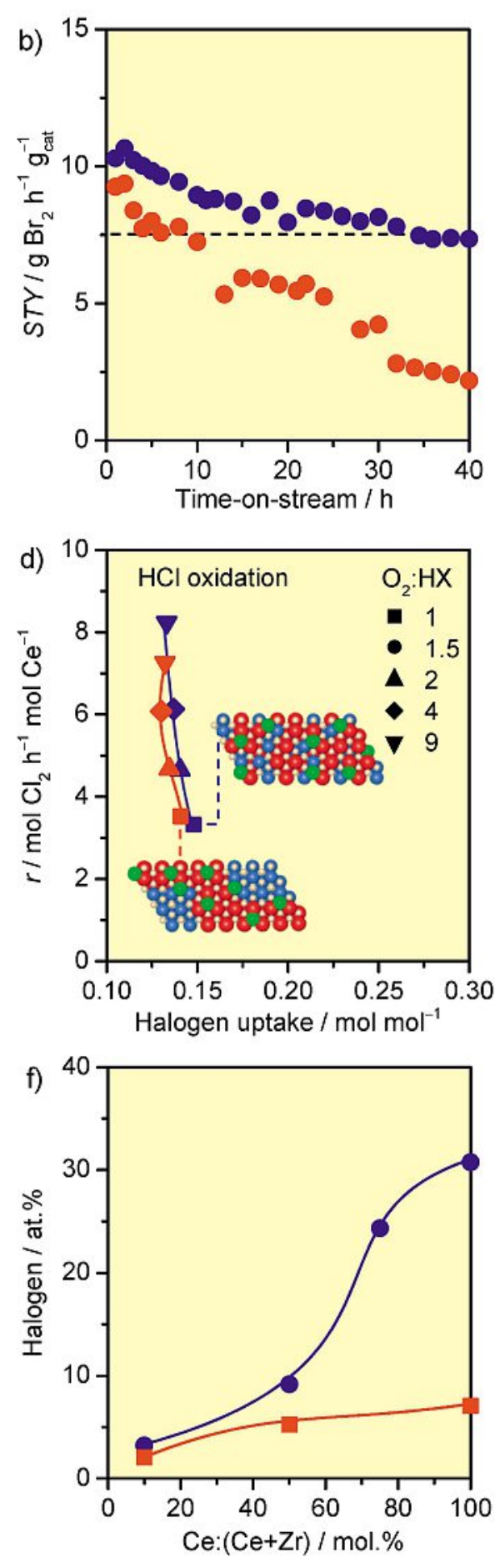

Fig. 3. EDS mapping of different mixed Ce-Zr oxides (a). Activity versus time on stream (b) and halogen uptake at different oxygen partial pressures (c,d) for homogeneous (blue) and nonhomogeneous (red) mixed Ce-Zr oxides. Activity (e) and halogen content (f) versus Ce content of the homogeneous catalysts in $\mathrm{HCl}$ (red) and $\mathrm{HBr}$ (blue) oxidation.

was comparable over both materials and did not significantly change when reducing oxygen partial pressures. The bromine uptake of the non-homogeneous sample was up to $50 \%$ higher compared to the homogeneous counterpart (Fig. 3c). ${ }^{[13]}$ This indicates that the stability can be optimized by the atomic-level intermixing of the $\mathrm{Ce}$ and $\mathrm{Zr}$ phases apart from tuning the reaction conditions.

In order to assess the influence of the composition of the homogeneous ceriazirconia solid solution on the catalytic performance, $\mathrm{CeO}_{2}-\mathrm{ZrO}_{2}$ mixed oxides with variable $\mathrm{Zr}$ content were tested in $\mathrm{HCl}$ and $\mathrm{HBr}$ oxidation. ${ }^{[13]}$ The highest reaction rate over ceria-zirconia in both $\mathrm{HBr}$ and $\mathrm{HCl}$ oxidation was achieved with $\mathrm{Zr}$ contents between $c a$. 90 and 70 mol.\% (Fig. 3e) at which point the halogen content reaches a minimum (Fig. 3f). For pure $\mathrm{CeO}_{2}$ (i.e. $100 \mathrm{~mol} . \%$ ), the bromine content is about four times higher than that of chlorine, due to the stronger tendency for bromination than chlorination. As the bromine content is higher than that of chlorine, the optimum for the $\mathrm{HBr}$ oxidation seems to have further shifted towards a higher Zr content (Fig. $3 \mathrm{e})$, which underlines the distinctions in the optimal design of Ce- $\mathrm{Zr}$ catalysts for application in either $\mathrm{HCl}$ or $\mathrm{HBr}$ oxidation. In this respect, the $\mathrm{Ce}: \mathrm{Zr}$ ratio is the key optimization parameter to tune the stability of the $\mathrm{CeO}_{2}$-based catalysts.

\section{Conclusions}

The study of catalytic hydrogen halide oxidation is experimentally challenging, which presents significant demands for the mechanistic analysis and characterization of catalysts under working conditions. The combination of advanced techniques such as TAP and operando PGAA with theoretical calculations comprise an optimal approach to understand halogen chemistry on catalytic materials. This strategy enabled the rationalization of the exceptional activity of $\mathrm{TiO}_{2}$ and the stability issues of $\mathrm{RuO}_{2}$ - and $\mathrm{CeO}_{2}$-based catalysts in $\mathrm{HBr}$ oxidation. The comparison between $\mathrm{HBr}$ and $\mathrm{HCl}$ oxidation indicated that the catalyst design criteria applied in $\mathrm{HCl}$ oxidation cannot be directly extrapolated to the recycling of $\mathrm{Br}_{2}$. Thus, catalyst design should be tailored for each reaction. The investigation showed that the halogen coverage under working conditions is the best parameter to assess the catalytic performance, which also highlights the significance of PGAA for this research. The surface halogenation can be tuned by optimizing the reaction conditions or the catalyst formulation which provides the foundation for future work on developing more stable and active catalysts not only for halogen recovery, but also for other halogen-based reactions such as the oxyhalogenation of hydrocarbons.

\section{Acknowledgements}

The Swiss National Science Foundation (SNF project number 200021-156107) and the European Union's 7th Framework Programme (NMI3-II grant number 283883) are thanked for financial support. Dr. Detre Teschner and Prof. Núria López are thanked for the longstanding and fruitful collaboration on the halogen field.

Received: December 18, 2016

[1] a) J. Pérez-Ramírez, C. Mondelli, T. Schmidt, O. F.-K. Schlüter, A. Wolf, L. Mleczko, T. Dreier, Energy Environ. Sci. 2011, 4, 4786; b) C. Mondelli, A. P. Amrute, M. Moser, T. Schmidt, J. Pérez-Ramírez, Chimia 2012, 9, 66; c) E. McFarland, Science 2012, 338, 340.

[2] a) G. A. Olah, B. Gupta, M. Farina, J. D. Felberg, W. M. Ip, A. Husain, R. Karpeles, 
K. Lammertsma, A. K. Melhotra, N. J. Trivedi, J. Am. Chem. Soc. 1985, 107, 7097; b) P. F. Schubert, R. D. Beatty, S. Mahajan, 'Catalytic Bromine Recovery from HBr Waste', Environmental Catalysis, American Chemical Society, Washington DC, 1994, p. 405.

[3] a) A. P. Amrute, C. Mondelli, M. Moser, G. Novell-Leruth, N. López, D. Rosenthal, R. Farra, M. E. Schuster, D. Teschner, T. Schmidt, J. Pérez-Ramírez, J. Catal. 2012, 286, 287; b) A. P. Amrute, F. Krumeich, C. Mondelli, J. Pérez-Ramírez, Chem. Sci. 2013, 4, 2209; c) A. P. Amrute, G. O. Larrazábal, C. Mondelli, J. Pérez-Ramírez, Angew. Chem., Int. Ed. 2013, 3, 657.

[4] M. Moser, C. Mondelli, T. Schmidt, F. Girgsdies, M. E. Schuster, R. Farra, L. Szentmiklósi, D. Teschner, J. Pérez-Ramírez, Appl. Catal. B 2013, 132-133, 123

[5] G. W. Hooker, US Patent 2163877, 1939.

[6] M. Moser, L. Rodríguez-García, A. P. Amrute, J. Pérez-Ramírez, ChemCatChem 2013, 5, 3520.

[7] M. Moser, I. Czekaj, N. López, J. PérezRamírez, Angew. Chem., Int. Ed. 2014, 53, 8628.
[8] a) N. López, J. Gómez-Segura, R. P. Marín, J. Pérez-Ramírez, J. Catal. 2008, 255, 29; b) D. Teschner, R. Farra, L.-D. Yao, R. Schlögl, H. Soerijanto, R. Schomäcker, T. Schmidt, L. Szentmiklósi, A. P. Amrute, C. Mondelli, J. Pérez-Ramírez, G. Novell-Leruth, N. López, J. Catal. 2012, 285, 273; c) D. Teschner, G. Novell-Leruth, R. Farra, A. Knop-Gericke, R. Schlögl, L. Szentmiklósi, M. G. Hevia, H. Soerijanto, R. Schomäcker, J. Pérez-Ramírez, N. López, Nat. Chem. 2012, 4, 739.

[9] a) D. Crihan, M. Knapp, S. Zweidinger, E. Lundgren, C. J. Weststrate, J. N. Andersen, A. P. Seitsonen, H. Over, Angew. Chem., Int. Ed. 2008, 47, 2131; b) S. Zweidinger, D. Crihan, M. Knapp, J. P. Hofmann, A. P. Seitsonen, C. J. Weststrate, E. Lundgren, J. N. Andersen, H. Over, J. Phys. Chem. C 2008, 112, 9966.

[10] J. Pérez-Ramírez, E. V. Kondratenko, Catal. Today 2007, 121, 160.

[11] a) M. A. G. Hevia, A. P. Amrute, T. Schmidt, J. Pérez-Ramírez, J. Catal. 2010, 276, 141; b) A. P. Amrute, C. Mondelli, M. A. G. Hevia, J. Pérez-Ramírez, J. Phys. Chem. C 2011, 115, 1056; c) A. P. Amrute, C. Mondelli, M. A. G. Hevia, J. Pérez-Ramírez, ACS Catal. 2011, 1, 583 .
[12] R. Farra, M. García-Melchor, M. Eichelbaum, M. Hashagen, W. Frandsen, J. Allan, F. Girgsdies, L. Szentmiklósi, N. López, D. Teschner, ACS Catal. 2013, 3, 2256.

[13] M. Moser, G. Vilé, S. Colussi, F. Krumeich, D. Teschner, L. Szentmiklósi, A. Trovarelli, J. Pérez-Ramírez, J. Catal. 2015, 331, 128.

[14] a) K. Seki, Catal. Surv. Asia 2010, 14, 168; b) C. Mondelli, A. P. Amrute, F. Krumeich, T. Schmidt, J. Pérez-Ramírez, ChemCatChem 2011, 3, 657.

[15] M. Moser, C. Mondelli, A. P. Amrute, A. Tazawa, D. Teschner, M. Schuster, A. KleinHoffman, N. López, T. Schmidt, T. J. PérezRamírez, ACS Catal. 2013, 3, 2813.

[16] A. Toftelund, I. C. Man, H. A. Hansen, F. AbildPedersen, T. Bligaard, J. Rossmeisl, F. Studt, ChemCatChem 2012, 4, 1856

[17] M. Moser, V. Paunović, Z. Guo, L. Szentmiklósi, M. G. Hevia, M. Higham, N. López, D. Teschner, J. Pérez-Ramírez, Chem. Sci. 2016, doi:10.1039/C5SC04247J. 